\title{
Effect of Motivation and Trust on Knowledge Sharing and Effect of Knowledge Sharing on Employee's Performance
}

\author{
Dr. Mohammad Hossein Moshref Javadi \\ Faculty Member of Business Administration, University of Isfahan, Iran \\ E-mail: MHMJ20032003@yahoo.com \\ Nasim Darvish Zadeh \\ Instructor of Public Management, Boroojerd Branch \\ Islamic Azad University, Boroojerd, Iran \\ Moeide Zandi \\ Graduate Student, Management Department, University of Isfahan, Iran \\ moeidzandi62@gmail.com \\ Javad Yavarian \\ Graduate Student of Management, University of Isfahan, Iran \\ Jyavarian@Yahoo.com
}

Accepted: March 25, 2012 Published: April 21, 2012

Doi:10.5296/ijhrs.v2i1.1675 URL: http://dx.doi.org/10.5296/ijhrs.v2i1.1675

\begin{abstract}
Knowledge sharing is a process in which individuals exchange their knowledge (implicit and explicit) and they create new knowledge together. Knowledge is an Unlimited; unfailing and valuable source for organizations that cause to survive in competitive environment and can be used to achieve competitive advantage. We can say that survival power of today's Organizations is depending on their use of knowledge. Knowledge can be available to individuals and organizations, therefore, there must exit conditions in the organization that people be able to share their knowledge with other individuals. In such situation, organizations can improve employees performance and also organizations performance. Given that the gas company performs and provides services to the citizens, achieving such goals requires employees to have certain knowledge and sharing that with other employees. So the objective of this study is to determine the factors affecting on knowledge sharing (motivation and confidence) and its impact on employees performance in the Gas Company of Kurdistan Province. This study provides a model that includes variables such as motivation,
\end{abstract}


confidence, knowledge sharing and performance in which the first two variables have been studied as the factors affecting on knowledge sharing.

Statistical population of this study includes all of the executive employees in the Gas Company of Kurdistan province and statistical sampling included 124 people which were selected randomly. For collection of data a questionnaire was used. The standard questionnaire was used to design questions related to motivation, trust and knowledge sharing and to assess the employee's performance.

The results showed that the factors of motivation and confidence are considered as factors affecting on knowledge sharing behavior and they enhance knowledge sharing, therefor they should be taken into consideration. In addition, the overall indices of model showed that the presented pattern is a good theoretical model for determining the effect of knowledge sharing on employees performance in which the data supported the model. Generally the effect of above factors on knowledge sharing behavior and the effect of knowledge sharing on employees' performance in Gas Company was confirmed.

Keywords: Knowledge Sharing, Motivation, Trust, Employees' Performance

\section{Introduction}

The notions of organization and management thinkers in the last two decades are accumulated with ideas that all of them emphasize on change in organizations environment, business conditions and business techniques. The current era is knowledge and information era that is based on knowledge. Today's organizations are located in a competitive environment which results from widespread environmental and organizational changes. Environmental changes are so fast, and unpredictable that neglecting of them can deprive the organization from a competitive advantage which may encounter other organizations with certain opportunities. One of the most important environmental changes that affect on organizations is use of knowledge and sharing it among employees in the organization for improve their performance. In fact, knowledge is an endless source which creates preference or profits in the competitive environment. In this regard, identifying factors affecting on knowledge sharing in an organization is notable. Knowledge is seen as a protector factor of production, economic and social development. (Information Society Commission, p.18). The ancient and former economies were dependent on agriculture Knowledge, how to build and how produce. But technological advances changed the methods of use of the knowledge in economy.To some extent we are witnessed a fundamental change in the competitive advantage (World Development Report, 1999).

Knowledge is seen now as an important factor in creating wealth, Therefore, if the use of Knowledge is possible for everyone, those who can transform information into knowledge and they use this knowledge in products and services will be main actors who can benefit from that. Thus the need to maintain workers knowledgeable, facilitating them to gain knowledge, achieving and sharing knowledge in the organization is a major concern for those organizations that want to remain in the competitive world. In the era of knowledge, wealth is based on property of knowledge and ability in use of knowledge for production and improvement of new products and services (O.C.D, 1999). 


\section{Research literature}

Factors affecting on knowledge sharing are as of the following:

1: Trust: There is a lack of consensus among theorists and researchers regarding a definition of trust, but they all have emphasized on importance of trust. Router (1967) indicated that trust is an expectancy held by an individual or group of words, promises, verbal or written statements of another individual or group. Lewis and Wigert (1985) expressed that trust is feeling of confidence and security in the caring responses of the partner and the strength of the relationship. Zaker indicated that trust includes a set of shared expectations among individuals who are involved in an interaction. Many researchers have been considered various dimensions in defining the trust, but many of these elements are similar which with different labels have been noted (Baker, 2006). Mayer et al (1995) represented three elements in the definition of trust: ability, benevolence and trusteeship. Ability is a set of skills, competencies and features that enables a group to influence on a particular field. Benevolent is the extent that a dependable person wants to do good things for confiding person (the person who trusts) with no motivation of profit. And trusteeship means the confiding perception of dependable person, means that how much he/she is committed to principles accepted by confiding person. Trust is a basic factor in knowledge sharing (FranchyKastl, 2004). Sharing knowledge is one of main concerns of today's organizations and in knowledge-based economy creates competitive advantage for organizations. However, organizations still have no mechanisms to encourage employees to share knowledge, Knowledge is valuable and knowledge sharing behavior is a type of social interaction at work (Davenport and Prusak, 1998). It can be expected that if knowledge owners do not receive the potential benefits, they will not share their knowledge anymore. A financial reward system is not enough to encourage staff to exchange of their knowledge, since the main determinant of social interactive relationships is trust (Vasco and Faraj, 2005). Thus, trust between individuals when an employee takes the decision to share knowledge, is considered the main factor. The researchers during many studies found that trust is a key variable for knowledge sharing and knowledge sharing can occur when people have trust to each other. Managers and other members share their knowledge only with individuals who they have trust them. When relationships are based on trust, people are more eager to provide useful knowledge. Also, people are more eager to listen and absorb staff's knowledge (Mayer et al, 1995). A human factor such as trust is a major component to obtain effective knowledge and also is an attribute to enhance of performance. When an organization has cooperation and support systems for trust, knowledge sharing and trast will become easy in the organization, in which this not only improves relationship between employees and management, but also makes more effective and efficient performance which eventually results in output increase. (Sewkaran, 2008). 
Motivation: Knowledge sharing is an important part of creating competitive advantage based on knowledge management. (Argot and Ingram, 2000).Knowledge sharing can be studied at the individual, group and organizational levels, Organizational and group knowledge sharing has rooted in individual behavior and director of that behavior (the purpose is motivation for knowledge sharing). The arguments that are claiming the relationship between organizational variables such as human resource activities, organizational outputs, and organizational knowledge sharing levels, should be consider the mechanisms of individual level that includes motivation, perception, and individuals behavior and interaction among individuals. Knowledge sharing often involves mutual interaction among individuals, which covers knowledge transmission and receives. The reason that staff do not like to share their knowledge, may be due to lack of incentives, or they may see knowledge sharing more difficult than others or they may know that probability of success is low, or may even feel that their colleagues do not want learn something from them.(Siemsen et al, 2007).

In the knowledge-based organizations, ability, knowledge, experience and personal skills are essential factors that add values to the organization. Accordingly, how to share these capabilities to organizational goals can determine the person real value. Therefore, the reward and compensation systems in these organizations should be assigned based on individual abilities and capabilities and its relationship with group and organizational goals. Lack of attention to such matter in knowledge-based organizations makes individual facing with the fundamental challenge and ultimately persuades him to find another or better position, if this problem is not solved, it will lead to desertion ultimately. Generally, there are various reward and compensation systems, including: Job-based payment, individual performance-based payment, gradual increase of salary, volume payment, dividends, and etc, which have different roles and impacts on maintaining knowledge workers. So designing the good payment system is a determinant factor in maintaining the knowledge staff (Ghadirian and Noble, 19 85).

Alwani (2005) stated that innovations of knowledge management in Bahrain organizations are so weak because they have increased the use of technology, whereas the issues related to organizational culture and development are ignored.

In addition, the success of knowledge sharing in many government projects is due to a combination of internal and external factors and the use of networks in an organization is a key factor for knowledge sharing (Barnard, 2005). Those organizations that like to be successful in transforming of knowledge, their achievement to developmental goals and strategies must create a culture of knowledge sharing that includes the following three criteria: Motivating, persuading, and stimulating of employees to obtain, distribute and transmit new useful knowledge and application of it. Open and flat organizational structure will facilitate the flow of knowledge, processes and resources creates organizational culture of continuous learning. In addition, the clear relations between goals and strategies related to knowledge sharing activities and the leader who provides instructions and feedback processes are needed as well. Eventually, advanced technology which provides knowledge is required for all of the 
people who need it for providing an appropriate field.

\section{Knowledge sharing}

when new knowledge acquired, it should de transfer to other parts of the organization that need new knowledge and is useful in that section. Without this stage, the knowledge has very little effect on the organization. As a result, transfer of knowledge in the appropriate time and place is most important part of storing the knowledge in an organization (Lee and Lee, 2008). Knowledge sharing is a set of behaviors including the exchange of information and knowledge to help others related to their job. Knowledge sharing like the organizational citizenship behavior is a kind of optional and voluntary organizations. One of the methods of measuring knowledge management is knowledge sharing (including tacit and explicit knowledge) (Sajjadi \& et al, 1389).

Knowledge sharing is seen as a positive motivating force in the organization. In fact, knowledge sharing is different from information sharing. Information sharing means to manage information in all overof the organizational levels (such as financial statements), while knowledge sharing is a reciprocity, information sharing can be non-reciprocal and unexpected (Conley and Klway, 2003).

Knowledge sharing among individuals is a process that easily and directly is not visible and observable, knowledge sharing is a process in which individuals exchange their knowledge (implicit and explicit) and together create new knowledge (Rio et al, 2003). In a broader concept, knowledge sharing covers relationships among all types of knowledge, including explicit knowledge (information, know-how, know-who) and tacit knowledge (Zawya, 2009). Knowledge sharing occurs when a person is actually in action interested helping others to develop their competencies (Senge, 1990). Therefore, knowledge sharing help persons tendency in an organization to share whatever they have and obtained, (Zawya, 2009). Bartol and Sryvasta (2002) have defined knowledge sharing as activities which through it the employees transfer relevant information to others in the organization. Knowledge sharing is most important part of knowledge management. The ultimate goal of knowledge sharing is to transfer knowledge toincrease assets and organizational resources. (Yang, 2006). If knowledge is shared in the organization, it creates competitive advantage for organization. Interactions among knowledge owners in the organizations makes them more innovative compared with the knowledge thatwas available to a person (Nita, 2008). Ipe (2003) stated that the creation of knowledge base in the organization requires the exchange of individual knowledge, assessment and integration of knowledge with other people. Individuals in the organization uses the knowledge in doing their daily activities and the organization should facilitate the knowledge sharing, because if employees leave the organization, this knowledge will be lost. Even when people stay in the organization, if the organization does not provide mechanisms to facilitate knowledge, then organization can't understand the existing knowledge and will not use it (Nita, 2008).

Nonako and Takochy (1995) expressed that we need to see knowledge sharing as an investment in organization. Knowledge is a key factor for organizational learning in all of the 
organizational levels; which recently is most important factor in organizations competitiveness. The main concern is that most organizational knowledge is located at the individual level (Nita, 2008). There are two aspects to evaluate knowledge sharing: providing the knowledge and acceptance of it. Furthermore, knowledge sharing among individuals is a process in which preserved knowledge by individuals convert to an understandable, learnable and applicable form to others. Use of this word for knowledge sharing indicate that process of knowledge presentation in a usable form for others requires conscious work on those who possess knowledge (Nita, 2008).

Knowledge sharing is a new paradigm in organizations (Barnard, 2005) and trust among employees and employer is needed for enhancing performance (Franchy Kastl, 2004).

\section{Organizational performance}

Most of the organizations included ( profit or non- profit, governmental or private), have accepted the principles of performance management to succeed. Performance evaluation is defined differently for each organization. Ravo indicated that performance is whatever expected from individuals or groups to do in a time framework which includes different dimensions such as input, output, time, quality, and cost. Due to different dimensions, there is not overall an accepted model as the best model to evaluate performance (movahed, 2009). Therefore, we can evaluate the performance in two levels: individual performance or employee performance and organizational performance. Organizational performance is indicated as of the extent to an organization that can satisfy staff expectations and satisfaction (Norton, 1992). Andresen (1994) expressed that the best way to enhance organizational performance is to increase the effectiveness, in which knowledge sharing plays an important role in enhancement of organizational effectiveness. Individual performance is defined as a background of person consequences or works that he/she had done (Armstrong, 1999). Quantitative models have been developed by researchers to evaluate the individual performance. Bratunn \& Gold (1994) provided a model of individual performance by three variables: these variables include: knowledge, skills, and competencies which each worker should have it. Also, Towi (2001) provided a model of performance which include input, process, and output. The input includes worker knowledge, skills and professions. The process supports behaviors during work time, and output is particular and measurable products that are produced by a worker. These three levels will results in performance together. Performance evaluation that is used as a tool to measure the performance has two purposes simultaneously: Employee development and improvement of organizational performance. The purpose of performance management is improving organizational performance through development of individuals and teams performance.

\section{Research hypotheses}

1 - Motivation affects knowledge sharing among employees in Gas Company of Kurdistan Province

2 -Trust affects knowledge sharing among employees in Gas Company of Kurdistan Province. 
3 - Knowledge sharing affects employee's performance in Gas Company of Kurdistan Province.

\section{Research Model}

Based on discussions related to variables in the research literature, research model is developed as of the following:

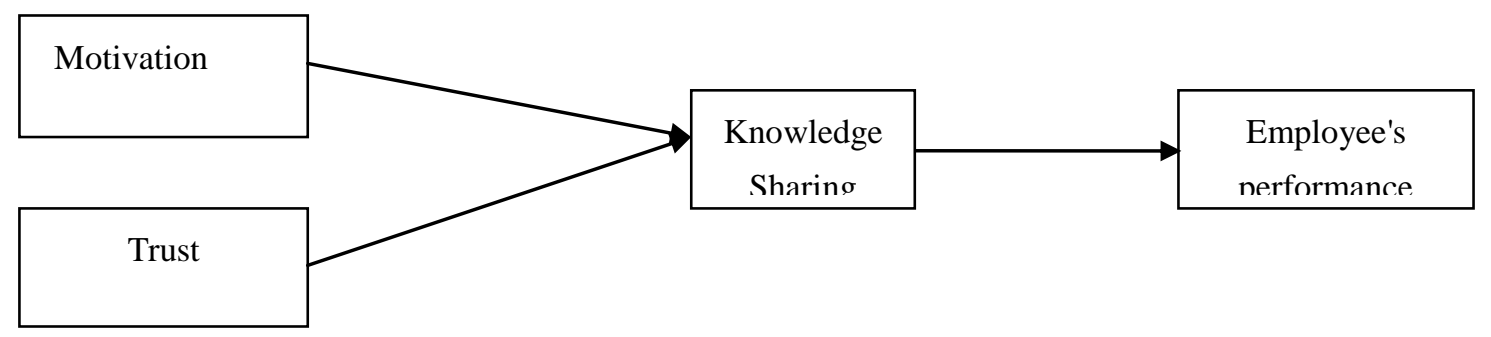

Figure 1: Research Model

\section{Research Methodology}

Since the purpose of this study was to determine causal relationships among variables of trust, motivation, knowledge sharing and employee performance, this study with regards to its goal is considered an applied research and regarding to the method of collecting information is a descriptive-correlation research. Also regression model and path analysis were used in this study.

\section{Data collection tools}

The main tool to gather data was questionnaire, validity of questionnaire has been approved and its reliability has been calculated by Cronbach alpha which its value for total questionnaire was 0/959 that shows the questionnaire is reliable.

\section{Statistical population and sample of research}

Population of this study consisted of all of the administrative employees in Gas Company of Kurdistan province. Community size was 220 people who were randomly sampled. Sample size was calculated by the formula of limited population, which was equal to124.

\section{Data analysis}

Total appearance of sample including mean, standard deviation and t-test ( $\mathrm{t}$ value $=3$ ) is shown in Table 1. 


\begin{tabular}{|c|c|c|c|c|c|c|c|}
\hline \multicolumn{2}{|c|}{$\begin{array}{r}\text { Confidence interval } \\
\text { of the difference }\end{array}$} & \multirow[t]{2}{*}{ significant } & \multirow[t]{2}{*}{$\begin{array}{r}\text { Freedom } \\
\text { degree }\end{array}$} & \multirow[t]{2}{*}{$\mathbf{t}$} & \multirow[t]{2}{*}{$\begin{array}{r}\text { Std. } \\
\text { deviation }\end{array}$} & \multirow[t]{2}{*}{ Mean } & \multirow[t]{2}{*}{ Variable } \\
\hline Lower & upper & & & & & & \\
\hline 0.95 & 1.17 & 0.00 & 123 & 19.41 & 0.61 & 4.06 & Motivation \\
\hline 0.58 & 0.84 & 0.000 & 123 & 10.55 & 0.75 & 3.71 & Trust \\
\hline 0.47 & 0.71 & 0.000 & 123 & 10.02 & 0.65 & 3.50 & $\begin{array}{r}\text { Knowledge } \\
\text { Sharing }\end{array}$ \\
\hline 0.49 & 0.74 & 0.000 & 123 & 9.6 & 0.19 & 3.62 & $\begin{array}{r}\text { Employees } \\
\text { Performance }\end{array}$ \\
\hline
\end{tabular}

Overall indices of fit of path analysis are presented in table 1.

\begin{tabular}{|r|r|}
\hline Value & index \\
\hline 63.403 & chi-square (CMIN) \\
\hline 0.078 & $\mathrm{P}$ \\
\hline 0.963 & goodness of fit index (GFI) \\
\hline 0.036 & root mean square residual(RMR) \\
\hline 0.921 & comparative fit index $(\mathrm{CFI})$ \\
\hline 0.043 & root mean square error of estimation (RMSEA) \\
\hline
\end{tabular}

Table 4-8: overall fit indices of path analysis

Above table indicates the good fit of data with research model, to fit the data with research model, the goodness of fit index (GFI) should be higher than 0.9 and root mean square error residual (RMSEA) should be less 0.08. After confirming the fit of data with model can be paid to test of research hypotheses.

\section{Research hypotheses}

Table 2: Regression coefficients (test hypotheses)

\begin{tabular}{|llllrlr|r|}
\hline Result & $\boldsymbol{P}$ & $\begin{array}{l}\text { critical } \\
\text { Value }\end{array}$ & $\begin{array}{l}\text { value } \\
\text { Regression }\end{array}$ & & Hypothesis & $\begin{array}{r}\text { Hypothes } \\
\text { is } \\
\text { Number }\end{array}$ \\
\hline $\begin{array}{l}\text { Confirme } \\
\text { d }\end{array}$ & 0.00 & 10.76 & 0.27 & $\begin{array}{r}\text { knowledge } \\
\text { sharing }\end{array}$ & Motivation & 1 \\
$\begin{array}{l}\text { Confirme } \\
\text { d }\end{array}$ & 0.00 & 3.25 & 0.33 & $\begin{array}{r}\text { knowledge } \\
\text { sharing }\end{array}$ & 0 & Trust & 2
\end{tabular}




\begin{tabular}{|c|c|c|c|c|c|c|}
\hline $\begin{array}{l}\text { Confirme } \\
\text { d }\end{array}$ & $\begin{array}{l}0.00 \\
0\end{array}$ & 8.94 & 0.57 & $\begin{array}{r}\text { Employee } \\
\text { Performanc } \\
\mathrm{e}\end{array}$ & $\leftarrow$ & $\begin{array}{r}\text { Knowledge } \\
\text { sharing }\end{array}$ \\
\hline
\end{tabular}

The first hypothesis of research is about the effect of motivation on knowledge sharing. According to the results of Table II, the first hypothesis with significant of $\% 95$ is confirmed. The Effect Coefficient of these two variables is 0.27.Therefore, in the level of 5percent error, it is significant. So motivation on knowledge sharing has a significant effect. The second hypothesis is about the effect of trust on knowledge sharing.

According to the results in Table 2, the second hypothesis as the first hypothesis in level of 5 percent error with significant of 95 percent was confirmed. The effect Coefficient of these two variables was 0.23 , which means at the error level of 5 percent is significant. So, trust has a significant effect on knowledge sharing.

The final hypothesis of research is about the effect of knowledge sharing on employee's performance. According to Table 2 the critical value was 8.94 , so this hypothesis is confirmed. Also the regression coefficient is 0.57 , so, in the confidence level of 95 percent we can claim that performance is affected by knowledge sharing.

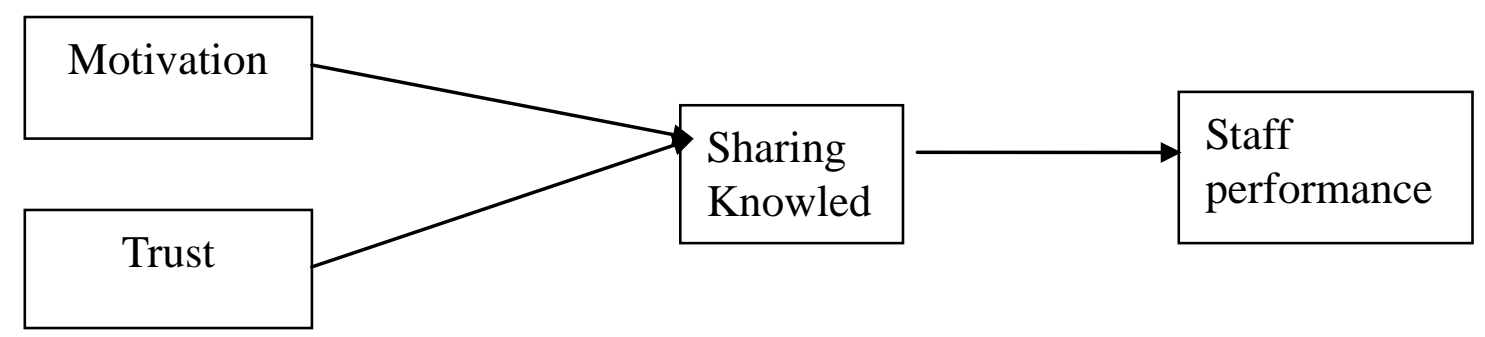

Figure 2: Path Analysis Model (All values are significant)

\section{Conclusion}

if people do not have enough motivation, we can't expect knowledge sharing among individuals in the organization exist, thus it is recommended that organizational managers try to provide an environment so people be motivated, and as a result they share their knowledge. Senge in 1990 has expressed that when people have interest and motivation for knowledge sharing, they can help others develop their competencies and facilitate knowledge sharing process within the organization. In the present study the effect of motivation on knowledge sharing in the first hypothesis was studied and the hypothesis was confirmed, namely motivation has a significant and direct effect on development of process of knowledge sharing in organizations. The value of coefficient of this hypothesis has been 0.27 . So we can claim that the employee's motivation as one of the factors affects knowledge sharing. The culture of knowledge sharing should include three criteria for organizations to be able to reach growth in goals and strategies. The employees motivation, encourage and stimulate to increase knowledge sharing. In the case of organization could achieve these three criteria, then it will be able to capture, transfer and apply useful knowledge.

As motivation and trust play a key role in the development of knowledge sharing process. If 
there is not trust in the organizations, relationships will be very limited and can be said that if there is not relationship among people, the knowledge will not share in the organization. When relations are based on mutual trust, people are more wishful to provide useful knowledge. Also, people are more wishful to listen to each other and gaining knowledge from each other. In the present study, the effect of trust on knowledge sharing was investigated. The hypothesis was confirmed. This means that the trust has a direct and significant effect on development of knowledge sharing in organization. The standard effect coefficient of this hypothesis was.033. Trust is a main component in acquisition of effective knowledge and an important attribute to enhance performance. When an organization has support and cooperative systems for trust, share and transfer of knowledge in organization will be more easy and, that not only improve employee's relationship and management, but it also results in an effective and efficient performance and eventually increase of output.

Regarding standard coefficient, it is concluded that the effect coefficient of trust has been higher than effect coefficient of motivation; this indicates importance of trust than motivation in the process of knowledge sharing. It should be noted that the difference is low, therefore the effect of motivation should not be neglected.

The best way to improve organizational performance is to increase the general effectiveness, increasing the effectiveness of development is possible through development of knowledge sharing, which means that knowledge sharing has an intermediary role in increasing organizational performance. As of the results of this study, knowledge sharing process has a significant and direct effect on staff's performance. This means that we can enhance employee's performance through encouraging employees to share their useful and helpful knowledge. 


\section{References:}

Armstrong, M. (1999). "A Handbook of HRM Practice", 7th Edition, London: Kogan Page. Barnard, Y. F. (2005). "Developing industrial knowledge management: Knowledge sharing over boundaries". Proceedings of the International Conference on Advances in the Internet, Systems and Interdisciplinary Research, pp. 1-6.

Bartol, K. M., \& Srivastava, A. (2002). "Encouraging knowledge sharing: The role of organizational reward systems". Journal of Leadership \& Organizational Studies, Vol. 9, No. 1, pp. 64-76.

Bratton \& Gold. (1999). "Human Resource Management: Theory and Practice". 2th Edition, London: MacMillan Press Ltd.

Ghadirian, A. \& Asili, G.(2006). "Knowledge worker management”. Journal of Management and Development, No.30, pp. 85-86.

Ipe, M. (2003). "Knowledge sharing in organizations: A conceptual framework". Human Resources Development Review, Vol. 2, No. 4, pp. 337-359.

Kaplan, R. S., \& Norton, D. P. (1992). "The Balanced Scorecard - Measures That Drive Performance". Harvard Business Review, Vol. 70, No. 1, pp. 71-79.

Lewis, J. D., \& Weigert, A. (1985). Trust as a social reality. Social Forces, Vol. 63, No. 3, pp. 967-984.

Mayer, R.C., Davis, J.H. and Schoorman, F.D. (1995), "An integrative model of organizational trust", Academy of Management Review, Vol. 20, No. 3, pp. 709-34.

McDermott, R. \& O'Dell, C. (2001). "Overcoming culture barriers to sharing knowledge". Journal of Knowledge Management, Vol. 5, No. 1, pp. 76-85.

Mohd, Bakhari Ismail. Yusof, Zawiyah, M. (2009). "The relationship between knowledge sharing, employee performance and service delivery in public sector organizations: A theoretical framework".Expert Systems with Applications, Vol. 3, No.1 .

Nita, Bogdan. (2008). "A dissertation on presented to the marshal globalism school of management organizational psychology division". San Diego Alliant International University. Nonaka, I. and Takeuchi, H. (1995). "The Knowledge Creating Company: How the Japanese Companies Create the Dynamics of Innovation". Oxford University Press, New York, NY.

Paul E. Tesluk, Edwin A. Locke, \& Kathryn M. Bartol. (2007). "A Multilevel Investigation of the Motivational Mechanisms Underlying Knowledge Sharing and Performance". Organizational Science, Vol. 18, No. 1, pp. 71-88.

Riege, A. (2005). "Three dozen knowledge-sharing barriers managers must consider". Journal of Knowledge Management. Vol. 9, No. 3, pp. 18-36.

Rotter, J. B. (1967). "A new scale for the measurement of interpersonal trust". Journal of Personality, No. 35, pp. 651-665.

Siemsen, Enno. Roth, Alenda V., \&Balasubramanian, Sridhar. (2007). "How motivation, opportunity, and ability drive knowledge sharing: The constraining-factor model". Journal of Operations Management. No. 26, pp. 426-445.

Small, C. (2005). An enterprise knowledge-sharing model: A complex adaptive 


\section{Al Macrothink}

International Journal of Human Resource Studies

ISSN 2162-3058

systemsperspective on improvement in knowledge sharing. (Doctoral dissertation, GeorgeMason University, 2005). ProQuest Dissertation and Theses, Vol. 66,No. 2, DAI-B, 1150.

Van den Hooff, B., Elving, W.J.L., Meeuwsen, J.M. \& Dumoulin, C.M. (2003). "Knowledge Sharing in Knowledge Communities". Communities and Technologies, pp. 119-142.

Yang, Jen-Te. (2006). " Knowledge sharing: Investigating appropriate leadership roles and collaborative culture". Department of Hotel Management, National Kaohsiung Hospitality College.

Zucker, L. G. (1986). Production of trust: Institutional sources of economic structure. Research in Organizational Behavior, No. 8, pp. 53-111. 